\title{
Sistem Otomatisasi Pelacakan Objek Astronomi Menggunakan Teleskop Berdasarkan Stellarium
}

\author{
Afif Aulia Rahman, Muhammad Rivai dan Tasripan \\ Departemen Teknik Elektro, Fakultas Teknologi Industri, Institut Teknologi Sepuluh Nopember (ITS) \\ e-mail:muhammad_rivai@ee.its.ac.id
}

\begin{abstract}
Abstrak-Stellarium merupakan software simulasi gambar 3D yang dapat menampilkan benda-benda angkasa secara detail, sehingga pengamat astronomi dapat mengetahui koordinat suatu objek angkasa melalui data yang disajikan oleh stellarium. Akan tetapi pencarian objek berdasarkan koordinatnya jika dilakukan pengamatan secara manual menggunakan teleskop akan membutuhkan waktu yang cukup lama. Oleh karena itu diperlukan suatu sistem yang secara otomatis dapat menggerakkan teleskop berdasarkan data-data yang diperoleh melalui stellarium. Sistem tersebut dapat dibangun dengan mengintegrasikan arduino, kamera, sensor potensiometer, motor servo dan motor dc. Stellarium mengirimkan data ke komputer berupa koordinat objek. Kemudian di komputer koordinat tersebut dikonversi dalam bentuk derajat dan dikirim ke arduino. Dengan metode fuzzy logic, arduino akan menggerakkan motor dc menuju objek berdasarkan data derajat dan sensor potensiometer. Kamera akan menangkap gambar real-time melalui teleskop dan ditampilkan ke layar monitor komputer. Kemudian komputer melakukan image processing yaitu autofocus dengan motor servo untuk memperjelas gambar dan tracking dengan menentukan titik tengah objek. Saat benda bergerak, kamera akan meng-update koordinat objek dan menggerakkan teleskop menuju koordinat baru objek tersebut. Berdasarkan pengujian, kesalahan hasil konversi sensor derajat azimuth rata-rata sebesar 0.6 derajat, sedangkan untuk altitude ratarata sebesar 0.6 derajat.
\end{abstract}

Kata Kunci-fuzzy logic, image processing, motor servo, motor dc.

\section{PENDAHULUAN}

$\mathrm{P}$ ERAN teleskop dalam bidang astronomi sangat berguna sebagai alat pengamatan dan observasi benda-benda angkasa secara langsung. Teleskop merupakan alat paling penting dalam pengamatan astronomi. Teleskop memperbesar ukuran sudut benda, dan juga kecerahannya [1]. Untuk melakukan pengamatan, terlebih dahulu harus mengetahui letak benda yang diamati. Sebagian besar teleskop yang digunakan oleh masyarakat umum belum memiliki perangkat tracking object jika benda bergerak.
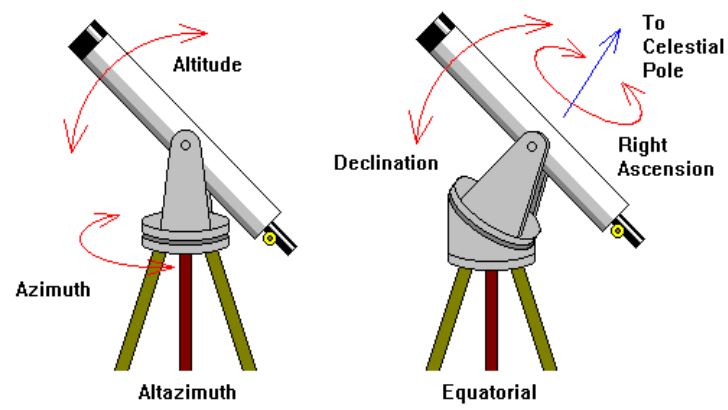

Gambar 1. Jenis mounting pada teleskop
Oleh karena itu pada penelitian ini dibuat suatu sistem teleskop yang dapat melakukan pelacakan objek astronomi secara otomatis. Inisialisai sistem dengan pengambilan database objek dari software stellarium berupa koordinat benda yang diamati. Kemudian dengan koordinat tersebut arduino akan menggerakkan motor beserta teleskop menuju target. Dengan mengunakan kamera yang terpasang pada teleskop dapat dilakukan tracking object jika mengalami perubahan posisi. Dengan sistem tersebut maka akan memudahkan proses pembelajaran bagi para pemula dan yang memiliki hobby astronomi. Selain itu para astronom professional akan terbantu dalam mengamati suatu objek tanpa harus melakukan perubahan teleskop secara manual.

\section{TEORI PENUNJANG}

\section{A. Mounting teleskop}

Mounting teleskop atau yang lebih familiar dikenal dengan "dudukan teleskop" terbagi dalam 2 jenis yaitu jenis mounting equatorial dan jenis mounting altazimuth [1]. Gambar 1 menunjukkan peletakan setiap jenis mounting teleskop. Mounting Equatorial bekerja menggunakan 3 buah sumbu yaitu sumbu RA, Deklinasi dan Equator. Sedang mounting altazimuth menggunakan 2 buah sumbu yaitu sumbu $\mathrm{X}$ atau altitude (atas bawah) dan $\mathrm{Y}$ atau azimuth (kanan kiri).

\section{B. Koordinat Horison}

Koordinat ini adalah tata koordinat yang paling sederhana dan paling mudah dipahami. Tetapi tata koordinat ini sangat terbatas, yaitu hanya dapat menyatakan posisi benda langit pada satu saat tertentu, untuk saat yang berbeda tata koordinat ini tidak dapat memberikan hubungan yang mudah dengan posisi benda langit sebelumnya. Karena itu menyatakan saat benda langit pada posisi itu sangat diperlukan dan tata koordinat lain diperlukan agar dapat memberikan hubungan dengan posisi sebelum dan sesudahnya [2]. Gambar 2 menunjukkan ordinat dalam koordinat horizon.

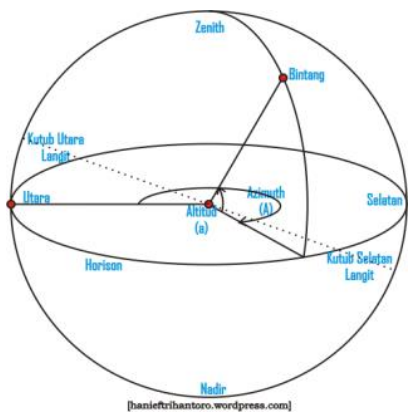

Gambar 2. Tata koordinat horizon 


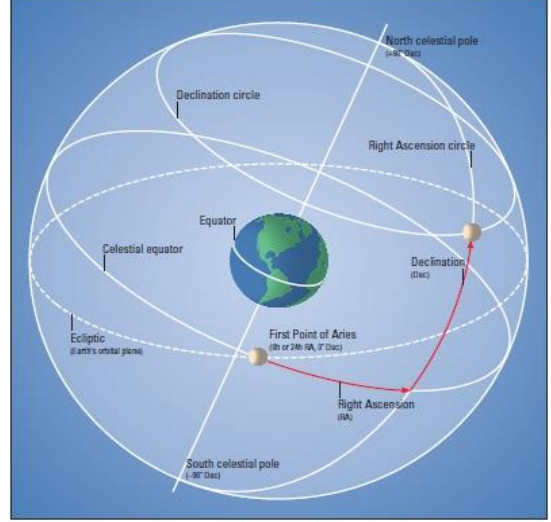

Gambar 3. Tata koordinat equator

\section{Koordinat Ekuator}

Tata koordinat ini merupakan salah satu tata koordinat yang sering digunakan dalam astronomi. Sistem koordinat ini dapat menyatakan letak benda langit dalam skala waktu relatif panjang. Sekalipun perubahan unsur-unsur koordinatnya relatif kecil terhadap waktu [2]. Gambar 3 menunjukkan ordinat dalam koordinat ekuator.

\section{Stellarium}

Stellarium merupakan proyek software "Open Source" yang mencoba membuat sebuah komputer menjadi planetarium virtual. Stellarium berlisensi GNU General Public License. Dengan lisensi tersebut pengguna bebas memakai, saling berbagi copy software, bahkan memodifikasinya karena disediakannya kode programnya. Gambar 4 menunjukkan tampilan stellarium.

\section{E. Metode Konvolusi}

Konvolusi citra adalah teknik untuk menghaluskan suatu citra atau memperjelas citra dengan menggantikan nilai piksel dengan sejumlah nilai piksel yang sesuai atau berdekatan dengan piksel aslinya. Dengan adanya konvolusi, ukuran dari citra tetap sama, tidak berubah [3]. Gambar 5 merupakan contoh ilustrasi metode konvolusi.

\section{F. Hough Transform}

Hough Transform merupakan suatu teknik untuk menentukan lokasi suatu bentuk dalam citra. Dalam implementasinya, Hough Transform melakukan pemetaan terhadap titik-titik pada citra ke dalam parameter space berdasarkan suatu fungsi yang mendefinisikan bentuk yang ingin dideteksi.

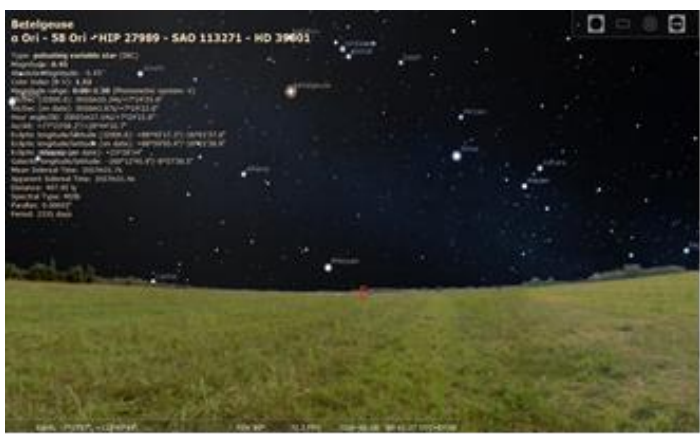

Gambar 4. Tampilan Stellarium

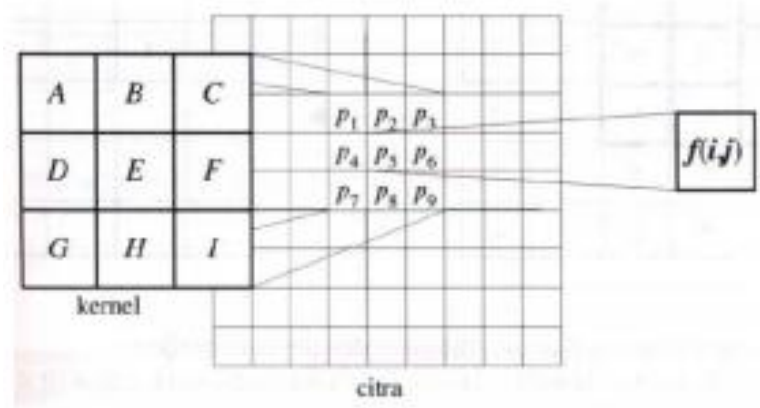

Gambar 5. Ilustrasi konvolusi

Hough Transform umumnya dugunakan untuk melakukan ekstrasi garis, lingkaran atau elips pada citra, namun dalam perkembangnnya, Hough Transform juga telah dapat digunakan untuk melakukan ekstraksi bentuk-bentuk yang lebih kompleks [4]. Gambar 6 menunjukkan proses hough transform.

\section{PERENCANAAN DAN PEMBUATAN ALAT}

Sistem merupakan teleskop reflector (Newtonian) yang dapat dikontrol pergerakannya melalui software, yaitu stellarium, yang telah terinstall pada perangkat komputer serta dapat mengikuti objek benda langit ketika bergerak. Teleskop dilengkapi dengan mikrokontroller Arduino sebagai pengatur gerakan motor dc dan motor servo. Dua buah motor dc sebagai penggerak derajat azimuth dan altitude teleskop, dua buah potensiometer sebagai sensor derajat azimuth dan altitude, sebuah kamera yang dapat mengambil gambar langsung dari cermin sekunder teleskop dan satu buah motor servo untuk mengatur jarak focus kamera. Diagram blok keseluruhan sistem ditampilkan pada Gambar 7. Cara kerja keseluruhan sistem adalah:

a. Stellarium mengirim koordinat $R A$ dan $D E C$ ke komputer.

b. Komputer melakukan konversi koordinat $R A$ dan $D E C$ menjadi koordinat Azimuth dan Altitude.

c. Komputer mengirim koordinat Azimuth dan Altitude ke arduino.

d. Arduino menggerakkan motor dc berdasarkan koordinat Azimuth dan Altitude dan mengatur kecepatan motor dc dengan metode fuzzy logic berdasarkan rule based yang telah dibuat sebelumnya.

e. Motor dc dan potensiometer dihubungkan oleh sebuah gear. Maka saat motor berputar, potensiometer juga akan ikut berputar. Arduino akan membandingkan nilai konversi derajat potensiometer dengan nilai derajat koordinat azimuth dan altitude. Jika nilai derajat potensiometer dan derajat koordinat azimuth dan altitude telah sama, motor akan berhenti. Jika nilai nilai perbandingan masih berbeda, motor akan terus berputar.

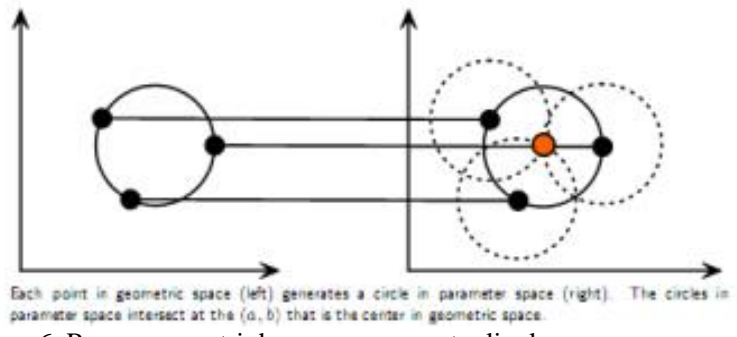

Gambar 6. Ruang geometri dan ruang parameter lingkaran 


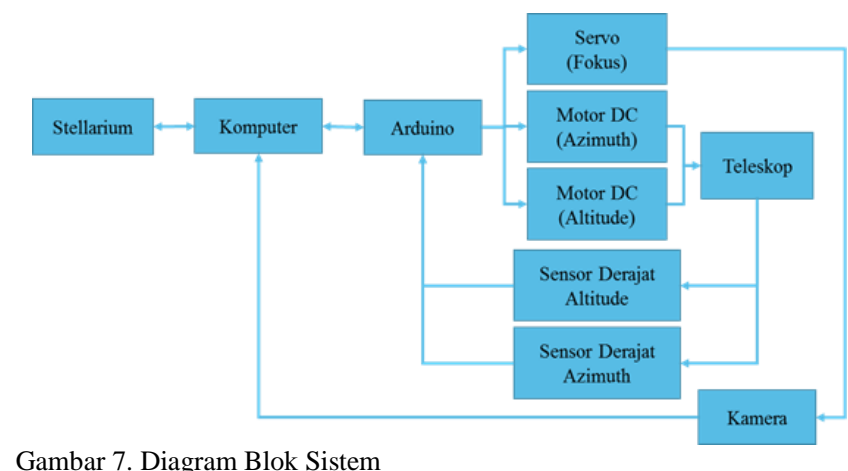

Gambar 7. Diagram Blok Sistem

f. Saat teleskop sudah menghadap koordinat yang dituju, komputer mengirim perintah ke arduino yang kemudian akan menggerakkan motor servo untuk mengatur focus kamera.

g. Penentuan focus kamera dilakukan dengan image processing melalui metode konvolusi. Komputer akan membandingkan nilai hasil konvolusi dengan nilai threshold yang telah ditentukan. Jika nilai hasil konvolusi sama dengan nilai threshold maka kamera sudah dalam keadaan fokus. Sedangkan jika kurang dari nilai threshold maka kamera belum dalam keadaan focus, sehingga motor servo akan terus berputar agar kamera menjadi focus.

h. Setelah proses penentuan focus selesai, kamera menangkap gambar real-time dari teleskop dan menampilkannya pada layar monitor komputer. Pada komputer kemudian dilakukan proses tracking dengan image processing melalui metode hough transform terhadap gambar yang ditangkap kamera.

i. Dengan metode hough transform komputer akan menandai benda langit yang berbentuk lingkaran dan menentukan titik tengahnya.

j. Saat benda langit yang ditangkap kamera bergerak, maka titik tengan objek akan bergeser. Komputer akan memerintahkan arduino untuk menggerakkan motor dc agar titik tengah objek berada pada tengah kamera, sehingga objek bisa terus diikuti pergerakannya.

\section{A. Perancangan Perangkat Keras}

\section{1) Motor DC dan Sensor Potensiometer}

Motor yang digunakan sebagai penggerak teleskop adalah dua buah motor dc yang dapat bergerak pada 2 arah secara berlawanan. Arah pergerakan motor ditentukan oleh pemberian tegangan DC pada kedua input motor. Sedangkan potensiometer digunakan sebagai sensor sudut derajat azimuth dan altitude teleskop

Gambar 8. Bentuk kamera
Motor dc dan potensiometer dihubungkan dengan sebuah gear untuk menggerakkan teleskop berdasarkan koordinat azimuth dan altitude. Ketika motor $\mathrm{dc}$ berputar, gear juga akan ikut berputar, akan memutar sensor derajat potensiometer.

\section{2) Kamera dan Motor Servo}

Kamera berfungsi untuk menangkap gambar dari cermin sekunder teleskop dan menampilkannya pada layar monitor komputer. Motor servo digunakan untuk mengatur jarak fokus pada kamera. Arah pergerakan motor servo ditentukan oleh pemberian sinyal oleh arduino pada pin control motor servo. Bentuk kamera ditunjukkan pada Gambar 8.

Penempatan kamera dengan meletakkan ujung kamera pada lensa okuler teleskop yang langsung menghadap cermin sekunder, sehingga kamera dapat mengambil gambar langsung dari teleskop.

\section{B. Perancangan Perangkat Lunak}

\section{1) Perangkat Lunak Pada Arduino}

Dalam diagram blok sistem pada Gambar 7 ditampilkan bahwa ada 3 tugas yang dilakukan oleh arduino yaitu membaca tegangan analog sensor potensiometer, mengatur motor dc untuk bergerak kearah koordinat yang dituju, dan mengatur putaran motor servo untuk fokus kamera.

\section{2) Fungsi konversi binary ke derajat}

Fungsi ini mengubah nilai pembacaan sensor potensiometer yang berupa nilai binary ADC menjadi nilai derajat. Nilai pembacaan ADC arduino mulai dari 0 sampai maksimum 1023. Untuk minimum derajat azimuth yaitu 0 derajat pada posisi menghadap utara. Sedangkan untuk minimum derajat altitude yaitu 90 derajat pada posisi berdiri tegak. Nilai ADC yang terbaca pada posisi-posisi tersebut kemudian akan dikonversi menjadi nilai derajat.

\section{3) Fuzzy Logic}

Logika fuzzy menggunakan rule base untuk dapat mengklasifikasikan himpunan data-data yang ada. Pada sistem ini klasifikasi yang dilakukan adalah nilai error derajat (e) dan perubahan error derajat $(\Delta \mathrm{e})$ sebagai input pada logika fuzzy. Error derajat (e) dan perubahan error derajat $(\Delta \mathrm{e})$ ditunjukkan pada Gambar 9 dan Gambar 10 Rule base fuzzy yang telah dibuat ditampilkan pada Tabel 1.

\section{4) Perangkat Lunak Pada Komputer}

Sistem perangkat lunak yang akan dirancang pada komputer adalah pembuatan interface pada visual studio, pengambilan koordinat dari stellarium, konversi koordinat RA dan Dec ke Azimuth dan Altitude, dan komunikasi serial arduino dengan komputer. Software yang digunakan adalah Microsoft visual studio dengan bahasa C\#.

Tabel 1.

Rule Based Fuzzy Logic [5]

\begin{tabular}{llllll}
\hline \hline & d_e0 & d_e1 & d_e2 & d_e3 & d_e4 \\
\hline e0 & ncepat & ncepat & ncepat & nsedang & zero \\
e1 & ncepat & nsedang & nlambat & zero & plambat \\
e2 & ncepat & nlambat & zero & plambat & pcepat \\
\hline \hline
\end{tabular}




\begin{tabular}{llllll}
\hline \hline e3 & nlambat & zero & plambat & psedang & pcepat \\
e4 & zero & psedang & pcepat & psedang & pcepat \\
\hline \hline
\end{tabular}

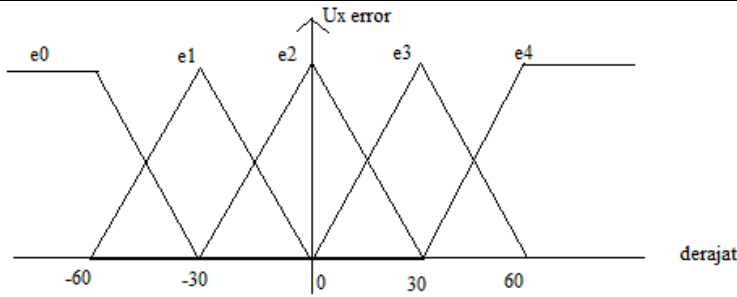

Gambar 9. Himpunan fuzzy input 1

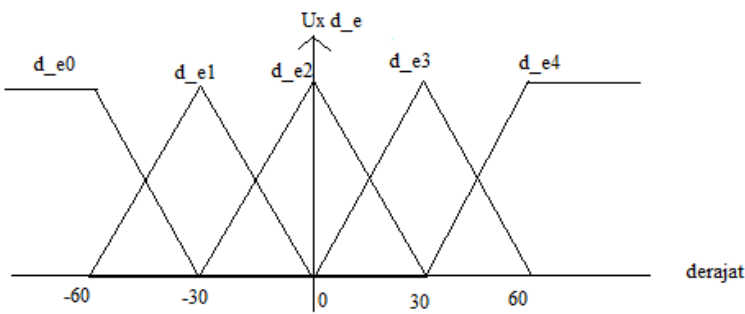

Gambar 10. Himpunan fuzzy input 2

\section{5) Interface pada visual studio}

Pembuatan interface pada visual studio bertujuan sebagai penghubung antara software stellarium dengan arduino. Terdapat dua mode, yaitu mode otomatis dan mode manual. Dimana mode otomatis akan menggerakkan teleskop berdasarkan koordinat yang diperoleh dari stellarium. Sedangkan mode manual akan menggerakkan teleskop berdasarkan nilai derajat yang diinputkan sendiri oleh pengguna (user) pada kolom altitude dan azimuth.

Kolom koordinat dari stellarium akan menampilkan koordinat RA dan Dec yang diperoleh dari stellarium. Kolom hasil konversi merupakan nilai hasil konversi dari koordinat RA dan Dec menjadi azimuth dan altitude. Kolom arduino digunakan untuk memonitoring nilai hasil konversi sensor dan nilai pembacaan ADC sensor potensiometer. Gambar 11 merupakan tampilan interface program yang dibuat pada visual studio.

\section{6) Pengambilan koordinat dari stellarium}

Pengambilan data koordinat dari stellarium dilakukan melalui Serial Command Protocol, yaitu berupa symbol dan huruf. Saat inisialisasi pertama kali stellarium akan mengirimkan command protocol ke komputer berupa:

:GD\# (Get Declination Telescope), returns: sDD*MM\# atau sDD*MM'SS\#

:GR\# (Get Right Ascension Telescope), returns: HH:MM.T\# atau HH:MM:SS\#

yang artinya Stellarium meminta koordinat Dec (Declination) dan RA (Right Ascencion) awal teleskop. Kemudian komputer akan mengirimkan koordinat awal teleskop. Saat memilih objek yang akan dituju oleh teleskop, stellarium akan mengirimkan lagi command protocol ke komputer berupa:

:SdsDD*MM\# (Set Target Object Declination), returns: 1 (Dec Accepted) atau 0 (Dec invalid)

:SrHH:MM:SS\# (Set target object RA), returns: 1 (RA Accepted) atau 0 (RA invalid) dimana sDD, MM merupakan nilai Dec yang akan dituju oleh teleskop dan HH, MM, SS merupakan nilai RA yang akan dituju oleh teleskop.

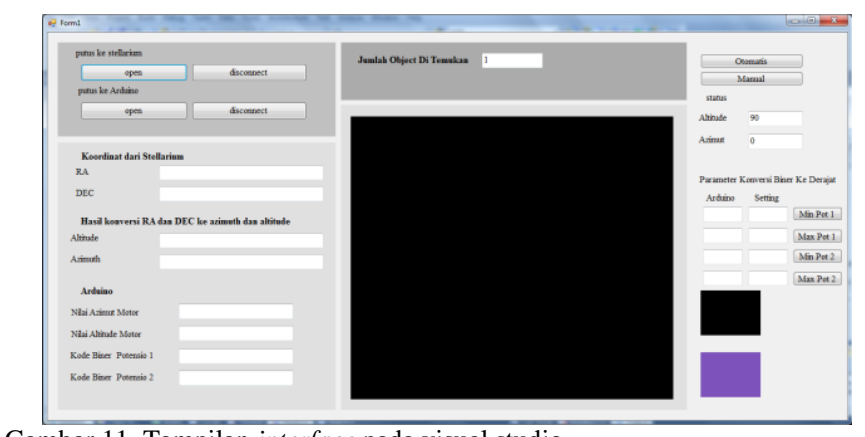

Gambar 11. Tampilan interface pada visual studio

7) Konversi koordinat $R A$ dan Dec ke Azimuth dan Altitude

Konversi koordinat RA dan Dec ke azimuth dan altitude diperlukan karena jenis teleskop yang digunakan yaitu jenis altazimuth, dimana perputarannya berdasarkan koordinat azimuth dan altitude. Ada 3 poin yang diperlukan untuk melakukan konversi, yaitu:

1. Nilai RA dan Dec, didapatkan dari stellarium

2. Waktu, didapatkan dari komputer

3. Lattitude (Garis lintang) dan Longitude (Garis bujur), didapatkan dari internet, contoh google maps.

Setelah didapatkan nilai yang diperlukan, kemudian melakukan konversi menjadi decimal dengan satuan derajat. Kemudian menghitung jumlah hari sejak J2000. J2000 merupakan referensi awal perhitungan hari yaitu sejak 1 januari 2000 AD jam 12.00 UT (Universal Time). Setelah itu menghitung LST (Local Sidereal Time) dengan rumus:

$\mathrm{LST}=100.46+0.985647 * \mathrm{~d}+$ longitude $+15 * \mathrm{UT}$

dimana, d adalah jumlah hari sejak J2000.

longitude adalah garis bujur

UT adalah waktu hasil konversi

Lalu menghitung HA (Hour Angle) dengan rumus:

$$
\mathrm{HA}=\mathrm{LST}-\mathrm{RA}
$$

dimana, LST adalah Loca Sidereal Time

\section{RA adalah RA hasil konversi}

Setelah didapatkan nilai hasil konversi, LST dan HA, selanjutkan menentukan azimuth dan altitude dengan rumus: $\sin (\mathrm{ALT})=$

$\sin (\mathrm{DEC}) * \sin (\mathrm{LAT})+\cos (\mathrm{DEC}) * \cos (\mathrm{LAT}) * \cos (\mathrm{HA})$

$\cos (\mathrm{A})=$

$\sin (\mathrm{DEC})-\sin (\mathrm{ALT}) * \sin (\mathrm{LAT}) / \cos (\mathrm{ALT}) * \cos (\mathrm{LAT})$ 


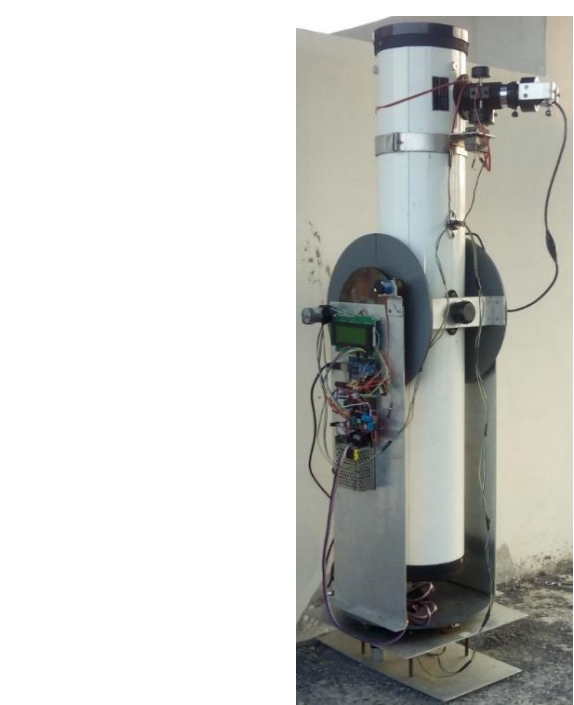

Gambar 12. Mekanik Keseluruhan sistem

\section{PENGUJIAN ALAT}

Pengujian dilakukan untuk mengetahui kinerja sistem secara keseluruhan. Pengujian sistem ini terdiri atas pengujian perangkat keras, pengujian perangkat lunak serta pengujian keseluruhan sistem. Gambar 12 menampilkan tampilan mekanik keseluruhan sistem.

\section{A. Pengujian perangkat keras}

\section{1) Pengujian sensor derajat potensiometer}

Pada pengujian pembacaan konversi derajat oleh sensor potensiometer dilakukan dengan kalibrasi secara manual. Kalibrasi dilakukan dengan cara mengarahkan teleskop secara manual pada posisi 0 dan 90 derajat untuk masingmasing koordinat azimuth dan altitude. Kemudian melihat nilai biner ADC yang terbaca pada kedua posisi tersebut.

Hasil pengujian konversi nilai ADC dilakukan dengan cara 15 kali pengambilan data dengan nilai derajat yang berbeda-beda, sehingga diketahui nilai error derajat. Posisi awal untuk azimuth adalah 0 derajat, sedangkan untuk altitude 90 derajat. Hasil pengujian ditampilkan pada Tabel 2 dan Tabel 3.

Tabel 2.

Hasil pengujian pembacaan konversi derajat azimuth

\begin{tabular}{|c|c|c|c|c|}
\hline No. & $\begin{array}{l}\text { Set derajat } \\
\text { (derajat) }\end{array}$ & $\begin{array}{l}\text { Hasil } \\
\text { (derajat) }\end{array}$ & konversi & Error (derajat) \\
\hline 1 & 0 & 0.8 & & -0.8 \\
\hline 2 & 10 & 10.8 & & -0.8 \\
\hline 3 & 25 & 25.8 & & -0.8 \\
\hline 4 & 30 & 30.5 & & -0.5 \\
\hline 5 & 45 & 45.3 & & -0.3 \\
\hline 6 & 60 & 60.5 & & -0.5 \\
\hline 7 & 75 & 75.6 & & -0.6 \\
\hline 8 & 90 & 89.7 & & 0.3 \\
\hline 9 & 135 & 134.5 & & 0.5 \\
\hline 10 & 180 & 179.5 & & 0.5 \\
\hline 11 & 200 & 199.5 & & 0.5 \\
\hline 12 & 220 & 219.3 & & 0.7 \\
\hline 13 & 270 & 269.2 & & 0.8 \\
\hline 14 & 310 & 309.2 & & 0.8 \\
\hline 15 & 360 & 359.3 & & 0.7 \\
\hline
\end{tabular}

Tabel 3.

Hasil pengujian pembacaan konversi derajat altitude

\begin{tabular}{|c|c|c|c|c|}
\hline No. & $\begin{array}{l}\begin{array}{l}\text { Set derajat } \\
\text { (derajat) }\end{array} \\
\end{array}$ & $\begin{array}{l}\text { Hasil } \\
\text { (derajat) }\end{array}$ & konversi & Error (derajat) \\
\hline 1 & 90 & 89.5 & & 0.5 \\
\hline 2 & 85 & 85.5 & & -0.5 \\
\hline 3 & 81 & 81.2 & & -0.2 \\
\hline 4 & 79 & 79.7 & & -0.7 \\
\hline 5 & 75 & 75.7 & & -0.7 \\
\hline 6 & 66 & 66.9 & & -0.9 \\
\hline 7 & 55 & 55.3 & & -0.3 \\
\hline 8 & 45 & 45.9 & & -0.9 \\
\hline 9 & 39 & 39.7 & & -0.7 \\
\hline 10 & 33 & 33.9 & & -0.9 \\
\hline 11 & 30 & 30.8 & & -0.8 \\
\hline 12 & 25 & 25.6 & & -0.6 \\
\hline 13 & 15 & 15.5 & & -0.5 \\
\hline 14 & 5 & 5.7 & & -0.7 \\
\hline 15 & 0 & 0.4 & & -0.4 \\
\hline
\end{tabular}

Dari hasil pengujian pembacaan hasil konversi sensor derajat potensiometer untuk derajat azimuth dan derajat altitude didapatkan kesalahan absolut untuk derajat azimut rata-rata sebesar 0.6 derajat. Sedangkan kesalahan absolut untuk derajat altitude rata-rata sebesar 0.6 derajat.

\section{B. Pengujian perangkat lunak}

\section{2) Pengujian konversi RA dan Dec}

Ketika memilih suatu objek, misalkan Mars, maka akan muncul data koordinat planet Mars. Berdasarkan stellarium, mars memiliki koordinat RA $=15 \mathrm{~h} 32 \mathrm{~m} 10.63 \mathrm{~s}$, Dec $=$ $21^{\circ} 08^{\prime} 28.3^{\prime \prime}$, azimuth $=244^{\circ}$, dan altitude $=54^{\circ}$. Nilai azimuth dan altitude pada stellarium tersebut yang akan menjadi nilai pembanding untuk hasil konversi RA dan Dec.

Dari hasil pengujian yang ditunjukkan pada Gambar 13 dan Gambar 14, diketahui hasil konversi koordinat RA dan Dec pada komputer telah sesuai dengan nilai pembanding pada stellarium. Sedangkan pembacaan sensor memiliki error sebesar $1^{\circ}$.

\section{3) Pengujian teleskop berdasarkan stellarium}

Pada pengujian ini teleskop akan digerakkan menuju objek yang dipilih melalui stellarium. Arah azimuth 0 derajat teleskop harus dihadapkan pada arah utara 0 derajat, sehingga teleskop dapat tepat menghadap objek. Pengujian dilakukan dengan menggerakkan teleskop ke arah bulan dan planet mars.

Kamera usb dipasang menghadap ke arah lensa okuler teleskop. Lensa okuler yang digunakan pada teleskop memiliki focal length $20 \mathrm{~mm}$. Sedangkan focal length teleskop $900 \mathrm{~mm}$.

\begin{tabular}{|c|c|}
\hline \multicolumn{2}{|c|}{ Koordinat dari Stellarium } \\
\hline RA & $15 \mathrm{~h} 32 \mathrm{~m} \mathrm{10s}$ \\
\hline DEC & $-21^{*} 08^{\prime} 28^{\prime \prime}$ \\
\hline \multicolumn{2}{|c|}{ Hasil konversi RA dan DEC ke azimuth dan altitud } \\
\hline Altitude & 54.2145826486304 \\
\hline Azimuth & 244.126394684342 \\
\hline
\end{tabular}

Gambar 13. Koordinat mars dan hasil konversinya 


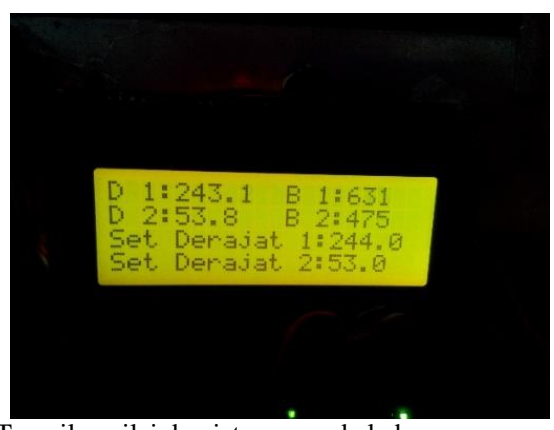

Gambar 14. Tampilan nilai derajat mars pada lcd

Pemilihan lensa okuler dengan ukuran focal length 20 mm dimaksudkan untuk mendapatkan pembesaran teleskop yang lebih kecil, sehingga objek yang memiliki jarak lebih dekat dengan pengamat seperti bulan dapat ditampilkan dengan ukuran penuh. Pembesaran teleskop diperoleh dengan rumus:

$$
\begin{aligned}
\text { Pembesaran } & =\frac{\text { focal length teleskop }}{\text { focal length lensa okuler }} \\
& =\frac{900 \mathrm{~mm}}{20 \mathrm{~mm}} \\
& =45 \mathrm{kali}
\end{aligned}
$$

Dari Gambar 15 dan Gambar 16 dapat dilihat bahwa bulan dan planet mars tidak tepat berada pada posisi tengah layar. Hal ini salah satunya dikarenakan error yang terdapat pada pembacaan sensor potensiometer. Selain itu perancangan antara motor dc dan gear penghubung dengan sensor potensiometer dapat mempengaruhi pengambilan gambar oleh teleskop.

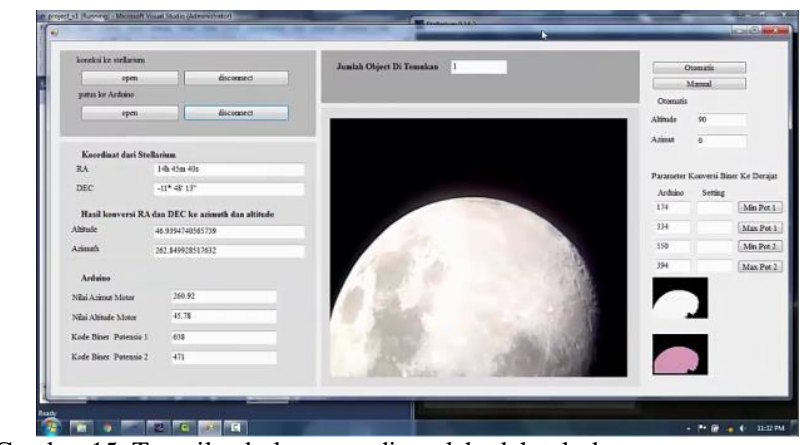

Gambar 15. Tampilan bulan yang diperoleh oleh teleskop

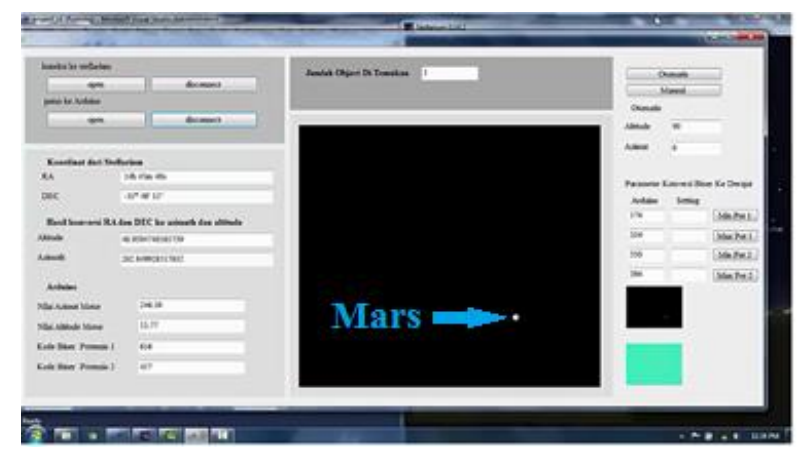

Gambar 16. Tampilan mars yang diperoleh oleh teleskop

\section{KESIMPULAN}

Dalam penelitian ini dirancang sebuah sistem berupa teleskop yang dapat melakukan pelacakan objek astronomi secara otomatis. Inisialisai sistem dengan pengambilan database objek dari software stellarium berupa koordinat benda yang diamati. Kemudian berdasarkan koordinat tersebut teleskop akan bergerak secara otomatis menuju objek yang dipilih pada stellarium. Teleskop dilengkapi dengan kamera usb untuk mengambil gambar dari lensa okuler teleskop dan kemudian ditampilkan pada layar monitor komputer. Berdasarkan pengujian, kesalahan hasil konversi sensor derajat azimuth rata-rata sebesar 0.6 derajat, sedangkan untuk altitude rata-rata sebesar 0.6 derajat. Perancangan motor dc dan gear penghubung dengan sensor potensiometer yang kurang akurat dapat menjadi faktor penyebab teleskop tidak dapat menangkap gambar objek yang diinginkan karena error pada putaran motor dc dan gear. Selain itu penempatan posisi teleskop pada sudut 0 derajat azimuth harus tepat dihadapkan pada arah utara 0 derajat agar teleskop tepat menghadap posisi yang dituju.

\section{DAFTAR PUSTAKA}

R. A. TeleskopSamir A. Abdul Kareem, Rizah Muhida, "Fuzzy Control Algorithm for Educational Light Tracking System," in 2nd International Congress on Engineering Education, 2010.

I. Dian, "sistem dan tata koordinat benda langit," 2011. [Online]. Available: http://fisika-astronomy.blogspot.co.id/ 2012/11/sistemdan-tata-koordinat-benda-langit.html.

O. J. Gazali Wikaria, Soeparno Haryono, "Penerapan Metode Konvolusi Dalam Pengolahan Citra Digital,” Binus University. Riwinoto, "Penggunaan Algoritma Hough Tranforms Untuk Deteksi Bentuk Lingkaran pada Ruang 2D," Politeknik Batam. T. A. . Neema D.D, Patel R.N, "Speed Control of Induction Motor using Fuzzy Rule Base,” Int. J. Comput. Appl., 2011. 